
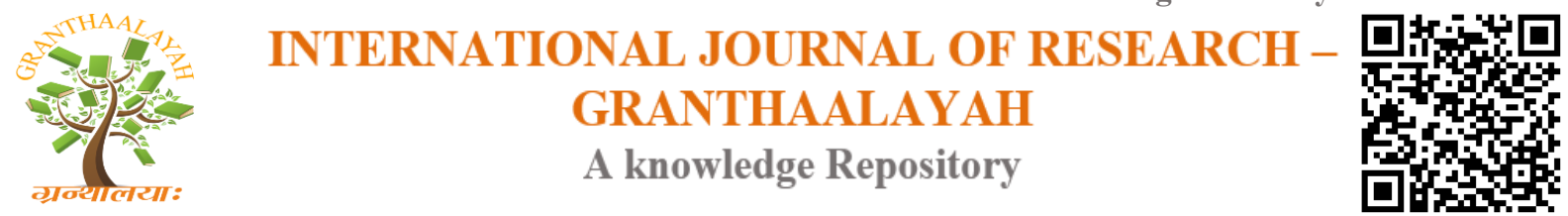

Management

\title{
HISTORY AND EVOLUTION OF STANDARDIZED TESTING - A LITERATURE REVIEW
}

\author{
Dr. Syeda Rakhshanda Kaukab ${ }^{* 1}$, Syeda Mehrunnisa ${ }^{2}$ \\ ${ }^{*}$ Education Department, Sindh Madressatul Islam University, PAKISTAN \\ ${ }^{2}$ Institute of Chartered Accountants of Pakistan, PAKISTAN
}

\begin{abstract}
This paper has been written with the intent of providing the history and evolution of the modern standardized testing while also highlighting the importance, pros and cons of standardized testing. In Pakistan, recently the higher education institution has established institute for development and implementation of standardized testing for admissions to the universities. It is for the first time that this is being introduced. Therefore, it appears in order that first the global development and need of standardized testing be researched upon and understood. This paper is an effort in combining the various sources on standardized testing in one paper.
\end{abstract}

Keywords:

Standardized Testing, Education, Higher Education.

Cite This Article: Dr. Syeda Rakhshanda Kaukab, and Syeda Mehrunnisa, "HISTORY AND EVOLUTION OF STANDARDIZED TESTING - A LITERATURE REVIEW” International Journal of Research - Granthaalayah, Vol. 4, No. 5 (2016): 126-132.

\section{INTRODUCTION}

\section{DEFINITION OF STANDARDIZED TESTING}

A standardized test is defined as a type of test that is "standard" or consistent in scoring across all candidates, who are made to take the test with the same questions and given the same amount of time. The prerequisite is that all variables be controlled. This allows for relative comparison of students' performances. While the format for these tests is most commonly multiple-choice as they can be scored quickly, questions can be included in the form of true-false questions, essay questions or short-answer questions. (1)

Due to the variety of their applications, standardized tests are designed to suit variable scenarios. Achievement tests are built to measure knowledge, skills and academic progress. Aptitude tests are more specific, to evaluate ability in a particular field or aspect and determine performance in a future setting. International-comparison tests are administered occasionally to samples of 
students in different countries to monitor achievement trends and compare educational performance. At a more personal level, psychological tests measure a person's social, mental and developmental characteristics and their cognitive abilities.

\section{HISTORY AND EVOLUTION OF STANDARDIZED TESTS}

The initial traces and records of standardized testing have been found to have originated from China. In China citizens desirous of getting into government jobs would do examinations for determination of their knowledge of the "Confucian philosophy and poetry" (2). Alfred Binet who was a French psychologist maybe considered the pioneer of the modern standardized testing concept. He began developing a test for intelligence which was furthered by Stanford and is now dubbed as the Stanford-Binet Intelligence Test.

In 1845 oral tests were conducted in American schools and Horace Mann came up with a vision for introducing written tests for which he approached the Boston Public School Committee (3). This was to allow for objective tests to be organized and given to students to give unbiased results concerning the level and quality of teaching in the urban schools as well as compare the schools and the teachers. Because of the success of the tests, it seemed as the competitive tests would be the best option for testing students. Written tests were the introduced across all cities in United States. This also led to the development of New York Regents Exams in 1865 (3).

Army Mental Tests that went by the name of Army Alpha and Beta tests, which were a type of aptitude test were conducted for soldiers joining US army during World War I (4). Initially the marking of the tests was done manually which posed a huge problem since this required hundreds of man hours of work. The first automatic test scanner was developed in 1936 which was the IBM 805 computer (2). This computer would detect the marks made by special pencils on the paper which gave a start to the technique of bubbling in answers.

Today SAT and ACT are the most widely recognized standardized tests. The start of SAT was at the Scholastic Aptitude Test by College Board in 1926. College Board was a not for profit group of universities, colleges and other educational organisations. The initial test was of 90 minutes and it had a mix of questions testing vocabulary and basic math mainly and consisted of 315 questions. However by 1930 the test had evolved into two parts test currently used as Verbal and Maths sections were separated. By the time the World War II ended, the SAT was accepted as the standard entry test for universities for all high school qualifiers. It remained in this form for the next 75 years until 2005. In 2005 the section on the analogies was replaced by a section on creative writing.

ACT was developed as a competitor for SAT by an education professor Everett Franklin Lindquist of the University of Iowa in 1959. ACT is an acronym for American College Testing. The ACT along with English, math and readings also tests the knowledge of scientific facts and principles. It is graded on scale from 0 to 36 . It also has a section which asks a student about their interests to guide them towards selecting a course of study. College Board also has SAT II which is for individual subjects like Biology, Physics, Chemistry, etc. Then there is also the four hour long Advanced Placement Tests for students in the United States who want to get exempted from some introductory courses in college. 


\section{BENEFITS AND DRAWBACKS OF STANDARDIZED TESTING}

Standardized testing has several benefits for national higher education commissions, individual educational institutions, teachers and parents of students who take part in these tests. These advantages are itemized as follows:

1) It helps identifies the strengths and weaknesses of students in relation to the national average of the students at similar age and level of education.

2) It enables to establish accountability of teachers and schools because generally the result of the tests becomes public record (5). Thus educational institutions and teachers who are not performing up to the mark can be subjected to disciplinary measures and evaluated further.

3) Standardized testing has improved educational time management, by focusing on learning outcomes of a particular aspect of the curriculum and the target areas for teachers. (5)

4) It allows comparison of the level of and achievement of students across schools, districts and provinces. Its standard nature allows this comparison to be made (6).

5) Standardized testing allows students across schools and districts to be at the same level as their peers and therefore switch schools without being ahead or behind. Similarly, standardized testing at college level would give equal opportunity to students belonging to all any city of the province to enter into a university.

6) The objective nature of standardized tests stems from the tests being scored by computers or by people who do not have any contact with student. Furthermore the tests are developed after several phases of review by experts and subjected to scrutiny to remove bias.

It is also important to note the drawbacks and limitations of standardized tests in order to be aware of the faults that may occur in relation to the results obtained.

1) Standardized tests determine the performance and achievement level of a student on a given day without considering the effects of other external factors. It may be possible that the student is not well on the day. Also it ignores the fact that several students simply do not do well on tests because of factors ranging from anxiety, family issues, etc.

2) In countries where standardized tests are at a higher degree of implementation, teachers only focus on teaching the tests (5) to show their own performance level and to skew the performance of the colleges and schools towards the positive scale. This may mean that teachers do not focus on certain areas of the curriculum which are important but are generally not covered by the standardized tests.

3) Since standardized tests are administered at any one particular point in time (6), they do not show the progress made by the students during the course of the year nor do they show the performance of the teachers and efforts put in by them to develop the students to the level that they have reached.

4) In regions of the world where standardized tests have been utilized over several years, funds given by the federal reserve to the schools has been linked to the performance of the schools as shown by the results of the standardized tests (5). This means that teachers and students are under pressure to perform on the tests resulting in decreased time for extracurricular activities. 


\section{CHALLENGES ENCOUNTERED DURING PREPARATION OF STANDARDIZED TEST}

While developing and implementing the standardized test, researchers, educators and test developers need to be mindful of the drawbacks and shortcomings of the tests. It is essential that the following be kept in mind to ensure preparation of an unbiased, valid test that could be implemented across the province or country as the case maybe:

1) A shortcoming or difficulty in the preparation of the test is the extent of the content or curriculum that is required to be tested by the standardized test (Popham, 1999). This makes it difficult for the developer of the test to decide whether to compromise on the content covered or the length of the test. Therefore the test needs to fulfill its purpose with a limited set of test questions or items as opposed to in an ideal situation where there is no time constraint.

2) During the process of development of the test, developers are tempted to ignore questions which generated a high percentage of correct answers by the control group of students. However this maybe because it is an important area of the curriculum wherein the teachers have stressed the importance upon students (7). This means that if the teachers do a good job in imparting or instructing a particular area of the curriculum then questions pertaining to this area would not make the final cut of the standard test.

3) Another challenge relating to these tests are the considerations for what determines how the student performs on these tests. There are three factors contributing to the success of students on these scores, namely:

a) Knowledge imparted in schools - what is actually required to be measured by the tests

b) The innate intellectual ability of a student - the natural intelligence and ability to deduce in students that does not have anything to do with the subject being tested

c) Out of school learning by students - knowledge gained by students, e.g. because of their better socio economic standing rather than the curriculum being taught to them (8)

\section{IMPORTANCE OF STANDARDIZED TESTING}

Although standardized tests have been controversial in their application, they have proved an important tool for teachers, school administrators and education officials. The objectivity of these tests has ensured that schools fulfill state standards in ensuring a competitive educational environment. In this way, students, teachers, schools and districts can all be evaluated on their performances. This can also lead to accountability of teachers and school administrations on educational standards set by the state, if a particular group of students is unable to reach the required score. (9)

The results of these tests are important as they measure the learning outcomes of the school. Although development of the tests are costly, however, their benefits outweigh their costs by a fair margin (8). 
"Utilizing a benchmark assessment based on standards provides teachers with a baseline for where students are individually as well as where the class is as a whole at selected checkpoints throughout the year" (10). If the tests are administered at the beginning of the year, the teachers will be aware of the learning and knowledge level of students coming into their class. They will know what they are required to teach to the students during the year. If the students are competent in a particular aspect of the curriculum then teachers may not need to spend time on that part and can direct their attention to areas where the students are lacking. Determining the timing of the tests are also important.

It may be possible to train teachers to develop assessments based on the standardized tests by using the same methodology so that for midterm and final assessments they can measure the performance of their students against the results of the standardized tests administered at the start of the year (10). The test scores will allow teachers to identify students early on who require more specific attention than others in terms of tutoring time, counseling, parents' involvement, etc.

The test results can provide information to the national education bodies as to which schools are consistently low achievers and therefore require extra attention by the bodies (11). This extra attention may include additional scrutiny to identify the factors causing low performance.

\section{WHAT STANDARDIZED TESTS ARE NOT SUPPOSED TO DO}

While standardized tests are good for determining the performance of schools and colleges against a national average and for establishing accountability of teachers and administration, it is important that these should not be used for deciding upon the quality of education being imparted by the schools and colleges. The reason for this is that internationally standardized tests have been developed by private for-profit institutes that come up with test items not answered by most students. This leads to a testing teaching mismatch as teachers may have emphasized on a topic they deem important while the test covered topics that were not given more than a cursory mention in the textbooks (7). Therefore, in this case the test would not show the quality of the education which maybe higher than reflected by the results of the test.

\section{USING BLOOM'S TAXONOMY}

Bloom's taxonomy is a set of three hierarchical models used to classify educational learning objectives into levels of complexity and specificity. It is classification of educational objectives used for developing higher level of thinking skills. It was developed by Benjamin Bloom in 1956. He proposed that all learning fits into one of the following psychological domains:

- Cognitive domain - this deals with the processing of information and mental skills

- Affective domain - this has to do with emotions, feelings and attitudes

- Psychomotor domain - this pertains to the physical skills and manipulation

The original levels cognitive domain of Bloom's taxonomy are as follows from low to higher order of thinking: 
- Knowledge

- Comprehension

- Application

- Analysis Synthesis

- Evaluation

In 1990s, a student of Bloom, Lorin Anderson revised the taxonomy and published a revised Bloom's Taxonomy as follows along with the key verbs associated with it:

- Remembering - Recognising, listing, describing, identifying, retrieving, naming, locating, finding

- Understanding - Interpreting, Summarising, inferring, paraphrasing, classifying, comparing, explaining, exemplifying

- Applying - Implementing, carrying out, using, executing

- Analysing - Comparing, organising, deconstructing, Attributing, outlining, finding, structuring, integrating

- Evaluating - Checking, hypothesising, critiquing, Experimenting, judging, testing, Detecting, Monitoring

- Creating - designing, constructing, planning, producing, inventing, devising, making

The standardized tests can be developed to include questions covering all levels of cognitive domain of Bloom's taxonomy (12). This enables the higher education commissions and educators to identify the cognitive learning level of students at the various grade levels as well as develop national average of cognitive level for students of each grade (13).

\section{REFERENCES}

[1] The Glossary of Education Reform. Standardized Test Definition. The Glossary of Education Reform. [Online] 2015. http://edglossary.org/standardized-test/.

[2] Fletcher, Dan. Standardised Testing - Brief History. United States : Time Magazine, 2009.

[3] Reconciling a Tradition of Testing with a New Learning Paradigm. Gallagher, Carole J. 1, s.l. : Springer, March 2003, Educational Psychology Review, Vol. 15, pp. 83-99.

[4] Gershon, Livia. A Short History of Standardised Tests. JSTOR Daily. [Online] May 12, 2015. http://daily.jstor.org/short-history-standardized-tests/.

[5] Columbia University. Pros and Cons of Standardized Testing. Office of Work/Life. [Online] Spring 2013. http://worklife.columbia.edu/files_worklife/public/Pros_and_Cons_of_Standardized_Testin g_l.pdf.

[6] Meador, Derrick. Examining the Pros and Cons of Standardized Testing. About Education. [Online] March 24, 2016. http://teaching.about.com/od/assess/a/Standardized-Testing.htm.

[7] Why Standardized Tests Don't Measure Educational Quality. Popham, W. James. 6, March 1999, Educational Leadership, Vol. 56, pp. 8-15.

[8] Winters, Marcus. Standardized Tests Are Costly, But Worth It. The New York Times. [Online] July 23, 2012. http://www.nytimes.com/roomfordebate/2011/05/30/testingstudents-to-grade-teachers/standardized-tests-are-costly-but-worth-it. 
[9] Study.com. The Importance of Standardized Testing. [Online] http://study.com/academy/lesson/the-importance-of-standardized-testing.html.

[10] Meador, Derrick. Classroom Assessment Best Practices and Applications. About Education. [Online] March 2016. http://teaching.about.com/od/assess/fl/ClassroomAssessment-Best-Practices-and-Applications.htm.

[11] Linnell-Olsen, Lisa. Why Schools Give Standardized Tests. Verywell.com: Parenting in Schools. [Online] April 12, 2015. https://www.verywell.com/why-schools-givestandardized-tests-2601506.

[12] Miller, Andrew. Beyond the Standardized Test: Aim Higher. Edutopia. [Online] May 20, 2014. http://www.edutopia.org/blog/beyond-standardized-test-aim-high-andrew-miller.

[13] Biology in Bloom: Implementing Bloom's Taxonomy to Enhance Student Learning in Biology. Crowe, Alison, Dirks, Clarissa and Wenderoth, Mary Pat . 4, s.l. : The American Society for Cell Biology, August 1, 2008, CBE Life Sciences Education, Vol. 7, pp. 368381 . 